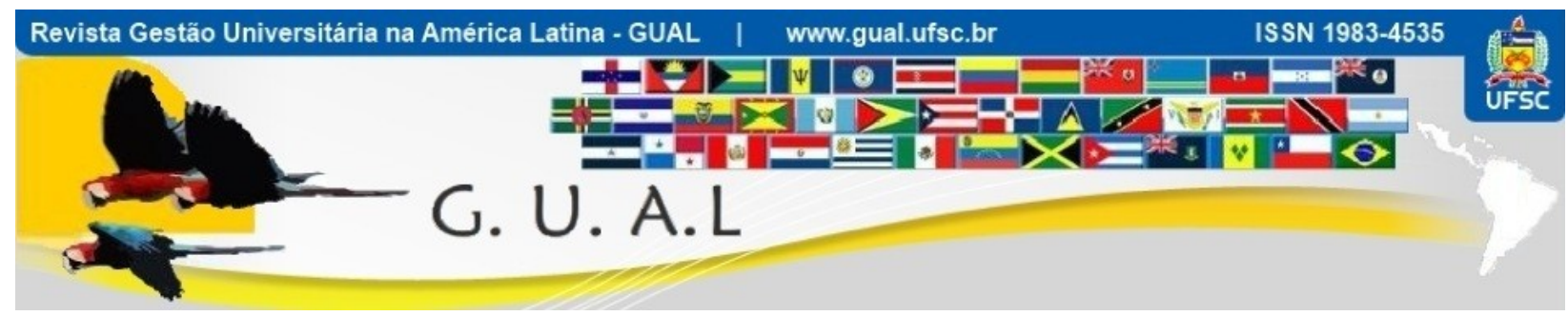

DOI: http://dx.doi.org/10.5007/1983-4535.2013v6n1p233

\title{
COMPORTAMENTO INTRAEMPREENDEDOR: UM ESTUDO EM INSTITUIÇÕES DE ENSINO SUPERIOR
}

\section{INTRAPRENEURIAL BEHAVIOR: A STUDY IN HIGHER EDUCATION INSTITUTIONS}

Suzete Antonieta Lizote, Mestre Universidade do Vale do Itajaí - UNIVALI lizote@univali.br

Jeferson Lana, Mestre Associação Educacional do Vale do Itajaí-Mirim- ASSEVIM jeff@,rovian.com.br

Susana Gauche, Mestre Centro Universitário para o Desenvolvimento do Alto Vale do Itajaí - UNIDAVI susanagauche@gmail.com

Miguel Angel Verdinelli, Doutor Centro Universitário para o Desenvolvimento do Alto Vale do Itajaí- UNIDAVI maverdinelli@gmail.com

Recebido em 09/novembro/2012

Aprovado em 10/janeiro/2013

Sistema de Avaliação: Double Blind Review 


\title{
RESUMO
}

O mundo global, de grandes avanços e descobertas, marcado pela evolução das telecomunicações e pelo surgimento de uma forte competição, exige que as organizações e as pessoas assumam novas posturas. Desta forma, as corporações que adotarem uma cultura intraempreendedora serão eficazes perante seu mercado de atuação, pois os empreendedores corporativos geram inovações contínuas dentro das organizações, oportunizando vantagens competitivas. Diante deste contexto, este estudo tem como objetivo descrever o nível de identificação dos funcionários com a organização em duas instituições de ensino superior e como esta variável psicossocial atua no relacionamento entre os fatores organizacionais e o comportamento intraempreendedor. Metodologicamente, a pesquisa é classificada como descritiva, pois identifica a conduta intraempreendedora segundo três escalas: comportamento intraempreendedor; identificação organizacional e fatores organizacionais. Para os dados analisados, foram encontrados valores significativos para a determinação do Comportamento Intraempreendedor pelos fatores organizacionais propostos, a saber: Apoio da Direção, Liberdade no Trabalho, Recompensas, Tempo Disponível e Incerteza nas Tarefas. Já quando inserida a variável mediadora "Identidade Organizacional", o modelo perde a validade. Para as IES estudadas, diferentemente do que propuseram Moriano et al. (2009), a "Identidade Organizacional" não atua como mediadora entre os fatores organizacionais e o Comportamento intraempreendedor.

Palavras-chave: Intraempreendedorismo, Conduta intraempreendedora, Instituições de ensino superior.

\begin{abstract}
The global world, known by breakthroughs and discoveries, marked by the evolution of telecommunications and the emergence of a strong competition, requires organizations and individuals to take new positions. Thus corporations that have embraced a culture of entrepreneurship will be effective in their performance market, once corporate entrepreneurs generate continuous innovation within organizations that brings competitive advantages. Given this context, this study aims to describe the level of identification of employees with the organization in two institutions of higher education and how this psychosocial variable affects the relationship between organizational factors and intrapreneurial behavior. Methodologically the research is classified as descriptive, once identified intrapreneurial behavior in three scales: intrapreneurial behavior, organizational identification and organizational factors. For the data analyzed were found significant values for determining the intrapreneurial behavior proposed by organizational factors, namely: management support, freedom at work, rewards, time available and uncertainty in tasks. Although, when added the mediator variable to be analyzed enclosed "organizational identity" model loses its validity. This means that, unlike what Moriano et al. (2009) proposed, organizational identity is not acting, for the institutions studied as a mediator between organizational factors and Intrapreneurial behavior.
\end{abstract}

Keywords: Intrapreneurship, Intrapreneurial behavior; Higher education institutions. 


\section{INTRODUÇÃO}

As organizações vêm-se preocupado cada vez mais com o intraempreendedorismo como uma estratégia competitiva (STEVENSON; JARILLO, 1990; KURATKO; IRELAND; HORNSBY, 2001). Inclusive os gestores corporativos, os líderes e os acadêmicos estão em busca de métodos inovadores para incentivar pessoas e equipes a serem mais criativos e, assim, tornar às organizações mais competitivas (KENNEY; MUJTABA, 2007). Na definição de Zahra e Covin (1995) o intraempreendedorismo apresenta duas dimensões: uma que inclui o compromisso da empresa em construir novos produtos ou processos, criando novos mercados, e outra dimensão abordando a renovação estratégica, que é a revitalização das operações.

A investigação nesta área, segundo afirmam Moriano et al. (2009), tem se concentrado na identificação das variáveis que influenciam a orientação empreendedora da organização, bem como a conduta intraempreendedora das pessoas (comportamento intraempreendedor). Referindo-se ao nível organizacional, sublinhou-se a importância de diferentes fatores como o tamanho da organização, estrutura, uso adequado de recompensas, o apoio da administração, e a disponibilidade de recursos. (ANTONCIC; HIRSRICH, 2003; HORNSBY; KURATKO; MONATGE, 1999; ZAHRA; COVIN, 1995).

Com relação ao comportamento individual dentro das organizações, as investigações têm focado nas diferentes características pessoais (SHABANA ,2010; KRAUSS et al., 2005) e, alguns autores, como Moriano et al. (2009), ressaltam que esse tema ainda é pouco estudado, e que as pesquisas não entram em profundidade no "por quê" algumas pessoas desenvolvem dentro das organizações um comportamento intraempreendedor e outras não.

Tentando preencher tal lacuna, este estudo vai replicar no ambiente organizacional universitário o modelo desenvolvido por Moriano et al. (2009), procurando se concentrar na identificação dos membros com a organização como uma variável psicossocial que influencia o desenvolvimento do comportamento intraempreendedor. Para tanto, será utilizada a modelagem de equações estruturais para avaliar se a influência de fatores organizacionais sobre o comportamento intraempreendedor é afetada pelo grau de identificação dos membros com a organização.

O desafio para as empresas manterem o espírito empreendedor de seus funcionários é uma constante, conforme o entendimento de Chieh e Andreassi (2007), na medida em que as mesmas crescem, alcançam a estabilidade e certo grau de sucesso. No caso das Instituições de 
Ensino Superior o desafio torna-se maior, pois de maneira geral são classificadas como organizações complexas (ANDRADE, 2002).

Para se compreender a complexidade da gestão universitária, Andrade (2006) destaca que se devem considerar fatores como o alto grau de autonomia dos professores, a dependência de habilidades individuais, a falta de planejamento, a diversidade e falta de clareza nos objetivos, assim como a improvisação das ações, dentre outros. Bertucci (1999) concluiu que os decisores, em todos os níveis, aparecem como intermediários entre o ambiente e a organização, e o desempenho dela estará diretamente influenciado pela forma como os gestores percebem e compreendem a universidade, como articulam e iniciam os processos e a maneira como incentivam e gerenciam as unidades organizacionais.

Diante destas pontuações, o objetivo deste trabalho é descrever o nível de identificação dos funcionários com a organização nas duas instituições de ensino superior (IES) consideradas e como esta variável psicossocial se relaciona com o desenvolvimento do comportamento intraempreendedor.

As IES, influenciadas também por mudanças em outros tipos de organizações, estão passando por transformações que, conforme coloca Andrade (2006), requerem melhores resultados e menores custos administrativos e operacionais, que permitam a formação de profissionais qualificados para atuarem no mercado de trabalho. Tais modificações exigem que as pessoas sejam incentivadas a desempenharem suas atividades com satisfação, desenvolvendo o espírito de criatividade e equipe, respeitando a autonomia e individualidade de cada um, para desenvolver um trabalho de excelência. Desta forma, os colaboradores estão sendo chamados a desempenhar atividades diferentes das tradicionais, pois como afirma Hashimoto (2006), a próxima década será marcada pela inovação. Consequentemente, surge a necessidade das IES procurarem identificar e aproveitar o potencial intraempreendedor de seus colaboradores.

O tema em questão e relevante por se tratar de um assunto importante na busca da identificação da conduta intraempreendedora dos colaboradores das instituições pesquisadas, as quais, com base nos resultados da pesquisa, poderão evidenciar seus pontos fortes e fracos em relação ao empreendedor corporativo e a partir daí, desenvolver atividades que estimulem a participação criativa e inovadora de seus colaboradores na busca de maior competitividade no fornecimento dos serviços educacionais. 


\section{EMBASAMENTO TEÓRICO}

\subsection{O EMPREENDEDORISMO E SUAS ORIGENS}

A origem dos termos empreendedorismo e empreendedor vêm da palavra francesa, com origem no latim, entrepeneur que significa "aquele que provoca brigas" e originou-se entre 1253 e 1289 (SOUZA, 2005). Deve-se observar também o surgimento do termo no contexto histórico. Filion (1999) elenca que até a década de 1980 havia duas correntes de pensamentos que abordavam o conceito de empreendedor, os economistas que o associavam à inovação e os comportamentalistas que se concentravam nos aspectos criativos e intuitivos.

Alguns estudos sobre empreendedorismo foram conduzidos com enfoque econômico, inclusive o termo tem sido considerado como centro do desenvolvimento da economia. A primeira definição de empreendedor, sob essa ótica, foi feita por Cantillon em 1755, significando especulador, à procura de melhor lucro, tendo a compra por um preço certo e a venda por um preço incerto (SCIASCIA; VITA, 2009). Destaca Filion (1999) que na visão de Cantillon, os empreendedores são pessoas que aproveitam oportunidades com a perspectiva de lucro, assumindo os riscos inerentes. Afirma ainda que o capitalista tem um lucro presumido, enquanto o empreendedor assume o risco, especulando a possibilidade de obter maior retorno.

Jean-Baptiste Say foi o segundo autor a se interessar pelos empreendedores. Para Filion (1988), Say deve ser considerado o pai do empreendedorismo porque foi o primeiro a lançar alicerces desse campo de estudo e a definir as fronteiras do que é ser um empreendedor na concepção moderna do termo. Em 1816, Say considerava o desenvolvimento econômico como resultado da criação de novos empreendimentos, e fazia diferença entre capitalistas e empreendedores, pois associava estes à inovação e via-os como agentes de mudança (FILION, 1999). O economista francês gerou a imagem de o empreendedor ser inovador, capaz de reduzir seus custos e, consequentemente, aumentar seus lucros pela implementação de inovações. (SCIASCIA; VITA, 2009).

Geralmente se relaciona empreendedorismo com inovação e, por isto, diversos economistas vem associado de modo mais agressivo esses construtos, procurando explicar a influência do empreendedorismo no desenvolvimento econômico, como salientam Paiva e Cordeiro (2002). 
Para Schumpeter os papéis centrais do empreendedor se fixam em três pontos: a inovação, o assumir riscos e a permanente exposição da economia ao estado de desequilíbrio, rompendo assim paradigmas (MAZZOTTI; HOELTGEBAUM; PERFEITO, 2006). Esta visão é clássica, sendo Schumpeter considerado como um dos autores mais importantes no que se refere a este assunto. Seguindo a linha iniciada por ele, e explorada por Abernathy e Clark (1985), considera-se que o empreendedorismo altera mercados, setores industriais, modelos de negócios e tecnologias por meio da inovação (MEURER; PREVIDELLI, 2003). Conforme Filion (1999), Schumpeter não foi o único a associar o empreendedorismo à inovação. Muitos economistas estavam interessados na compreensão do papel do empreendedor como mola propulsora do sistema econômico.

Cabe ressaltar também que muitas pesquisas sobre empreendedorismo foram feitas pelos sociólogos e psicólogos, onde seus olhares se voltaram para as características do empreendedor. Esta preocupação com o lado comportamental do empreendedorismo não havia acontecido em razão dos economistas se recusarem em aceitar modelos até então não quantificáveis, demonstrando os limites dessa teoria (FILION, 1999).

$\mathrm{O}$ primeiro conceito importante surgido na perspectiva comportamental foi à ideia de autoridade carismática, vista como processo evolutivo para a tendência de superar rotinas. A autoridade carismática seria uma oposição à autoridade tradicional, burocrática, no sentido de obrigação de regras, tornando-se um precedente para quebrar as regras. A partir desta ideia o empreendedor é ator na economia (SCIASCIA; VITA, 2004). Max Weber (1947) via os empreendedores como inovadores, pessoas cujo papel de liderança nos negócios inferia uma fonte de autoridade formal (FILION, 1999). Mas, McClelland (1971) foi o autor que realmente deu início à contribuição comportamental. O que despertou seu interesse em pesquisar comportamentos que levavam ao empreendedorismo foi o crescimento na época da União das Repúblicas Socialistas Soviéticas (URSS).

Segundo Filion (1999) aquele autor buscava explicações para a existência de grandes civilizações e também para o declínio das mesmas. McClelland (1971) enfatizava que o sucesso não consiste só no desenvolvimento de habilidades específicas, mas também habilidades atitudinais empreendedoras. Concluindo em que as pessoas empreendedoras possuem uma motivação diferenciada pela presença de uma necessidade específica: a realização (MAZZOTTI et al., 2006). Assim, pessoas que têm um alto desejo de realização dedicam mais tempo a tarefas desafiadoras e que envolvem riscos moderados, preferindo 
depender da própria habilidade para obtenção de resultados. (OLIVEIRA; GUIMARÃES, 2003).

O termo empreendedorismo remete assim a um estudo complexo devido à própria natureza do fenômeno e, em consequência, existem diferentes definições que enfatizam suas diferentes áreas (SCIASCIA; VITA, 2004). Uma delas é o intraempreendedorismo, que Antoncic e Hisrich (2003) descreveram com uma ação empreendedora dentro de uma organização. Por sua parte, Chieh e Andreassi (2007) sugeriram que o intraempreendedorismo associa-se ao desenvolvimento de novos produtos e processos ou bem à adaptação de um já existente.

Enquanto alguns autores afirmam que o empreendedorismo deve ser visto como uma busca em ter seu próprio negócio, outros trabalham o conceito de empreendedorismo corporativo, que implica na renovação estratégica e organizacional involucrando mudanças na gestão empresarial, privilegiando a inovação, a flexibilização e a criatividade.

\subsection{INTRAEMPREENDEDORISMO}

Atualmente, como afirma Shabana (2010), as organizações estão se reestruturando e repensando seus processos de trabalho interno, principalmente devido às pressões do mercado, provenientes dos consumidores, concorrentes, fornecedores, governos e, principalmente, das variáveis do macro ambiente. O intraempreendedorismo não é somente uma forma de buscar aumentar o nível de produtividade e inovação das organizações, conforme coloca Pinchot (1985), ele é uma forma de organização do trabalho e dos processos empresariais de forma mais integrada. Nesta mesma linha de pensamento, Filion (2004) destaca que para serem intraempreendedoras, as pessoas têm que ter um alto nível de compromisso com o que fazem e devem ser capazes, pelo menos, de sustentar a continuidade da execução da ação que iniciam.

Desta forma, Guilhon e Rocha (2000) colocam que, para atender às demandas competitivas do novo contexto organizacional, a liberdade de ação em todos os níveis da empresa, de modo participativo, deve ser a regra de conduta e orientação gerencial no processo de gestão permanente da mudança organizacional. Como afirmam Pryor e Shays (1993), as empresas proativas já caminham nesta direção, pois a descentralização na tomada de decisão já está sendo incorporada ao planejamento estratégico, com vistas à diminuição do custo operacional e a elevação da qualidade dos serviços/produtos que serão ofertados com a participação direta de seus funcionários. 
Examinando inovações bem sucedidas em grandes empresas, Pinchot (1985) identificou comportamentos empreendedores em alguns empregados, estes funcionários atuavam como agentes de mudanças em suas organizações, melhorando os processos e criando novas oportunidades de negócio, pelo que os denominou de empreendedores intracorporativos (intraempreendedores). $\mathrm{O}$ intraempreendedorismo refere-se a intenções comportamentais emergentes dos indivíduos que apresentam suas próprias ideias e, em seguida, as trazem para a vida na organização, com assistência e recursos da gestão (SHABANA, 2010). Assumindo riscos, procuram transformar uma ideia em um negócio lucrativo dentro do ambiente organizacional em que estão inseridos.

$\mathrm{O}$ intraempreendedorismo consiste em um sistema para acelerar as inovações dentro das organizações, como afirma Pinchot (1985), explorando oportunidades e visando ganhar retornos acima da média, através de um melhor uso dos talentos empreendedores dos seus colaboradores, os quais por sua vez, têm liberdade de ação mais restrita, já que não são os donos do negócio. Entretanto, conforme colocam Zilber e Brancalião (2008), essa ação deve levar em conta o ambiente onde a empresa está inserida e a identificação de oportunidades que possam gerar novos negócios.

Toda organização passa pelo enfrentamento da conquista de market-share e constante adaptação às mudanças no mundo dos negócios, e o intraempreendedorismo torna-se essencial para qualquer organização se sobressair. De forma mais incisiva Shabana (2010, p. 33) relata: "o intraempreendedorismo não é mais uma escolha, é a única atitude de sobrevivência”, pois, segundo ele afirma, a turbulência externa está forçando a transformação interna. Este comportamento de inovação, de explorar oportunidades deve estar incutido e institucionalizado nas organizações como um fator preponderante para o sucesso.

\subsection{COMPORTAMENTO INTRAEMPREENDEDOR}

A visão comportamental do empreendedorismo iniciou com Weber publicado originalmente em 1947, onde definiu que os empreendedores internos são pessoas inovadoras que possuem uma importante função de liderança no ambiente organizacional. Atualmente, segundo Filion (1999), não se fala mais em estabelecer um "perfil" do empreendedor corporativo de sucesso, mas nas habilidades que o mesmo deve ter ou desenvolver. Desta forma, infere-se que, o comportamento intraempreendedor permite à organização ser renovada, melhorando desta forma, a sua competitividade no mercado. 
Pinchot e Pelmann (2004) sugerem a criação de equipes intraempreendedoras dentro das organizações, ou o que eles também denominam "intraempresa", com a finalidade de incentivar o intraempreendedorismo. Para Hirsch e Peters (2004), o espaço ou ambiente para inovar deve ser estabelecido pela organização, estimulando, assim, novas ideias. Para tanto, a empresa deverá incentivar o trabalho em equipe, proporcionar os recursos e se manter comprometida com a cultura intraempreendedora.

Hornsby, Kuratko e Zahra (2002) identificaram cinco fatores estáveis da organização promotores do comportamento intraempreendedor, são eles: 1) apoio da direção, pois é essencial que a gestão aceite o comportamento intraempreendedor e também proporcione os meios e recursos necessários para desenvolver as ideias inovadoras; 2) liberdade no trabalho, ou seja, a autonomia, delegação de autoridade e responsabilidade, e tolerância de falhas; 3) recompensas baseadas no desempenho; 4) tempo disponível para criar novas ideias; e, 5) transparência das organizações quanto ao resultado esperado dos indivíduos.

Por outro lado, Pinchot (1985) evidencia também que cada colaborador interno deve assumir condutas que possibilitem o desenvolvimento de atitudes empreendedoras e proativas, e descreve o que ele chama dez mandamentos do intraempreendedor: lembre-se de que é mais fácil pedir desculpas do que permissão; faça o que for necessário para que seu projeto dê certo, mesmo que escape às atribuições de sua função; vá trabalhar todo o dia com o espírito de quem será demitido; forme uma equipe sólida; peça conselho antes de solicitar recursos; deixe de lado o orgulho da autoria, divulgue a credibilidade; ao quebrar regras, lembre-se dos principais interesses da empresa e de seus clientes; respeite seus patrocinadores; faça menos promessas e mais entregas e seja leal as suas metas, mas realista sobre os meios para atingi-las.

Ireland, Kuratko e Morris (2006) destacaram ainda que com o crescimento das organizações, frequentemente, a burocracia aparece impedindo a inovação e, às vezes, impedindo a capacidade da empresa para competir. Estes autores também identificaram que a maioria das empresas não tem uma cultura organizacional favorável ao espírito empreendedor, inibindo os funcionários com a implementação de políticas e procedimentos que reprimem os traços empreendedores. Como resultado, os funcionários deixam as organizações e perseguem os seus próprios empreendimentos.

Pesquisas nesta área identificaram os seguintes componentes principais do comportamento intraempreendedor: assumir riscos, inovação, proatividade e iniciativa pessoal, autonomia e realização de orientação (LUMPKIN e DESS, 1996; COVIN e SLEVIN, 
1991; KRAUSS et al., 2005). Destes comportamentos intraempreendedores no estudo de Moriano, et al. (2009), ao proporem seu modelo, se selecionaram dois componentes que nomearam como o coração do comportamento intraempreendedor: inovação e assumir riscos.

Por inovação, segundo Amabile (1997) entende-se a implementação de ideias originais e apropriadas para o desenvolvimento através da criatividade. Assumir riscos pode ser definido como a preferência por situações que podem ou não ter sucesso, sabendo-se que pelas situações não bem sucedidas pode haver consequências graves (GUILHON; ROCHA, 2000).

No entanto, deve-se salientar que o comportamento intraempreendedor ou seu próprio desenvolvimento pode ser reforçado ou limitado por ações e atitudes da organização. Como Drucker (2002) afirmou uma cultura favorável à formação de um espírito empreendedor, provoca em seus empregados uma busca constante pelo novo, pela melhor maneira de desenvolver algo, um aperfeiçoamento dia-a-dia, uma conduta que inclusive leva a dedicação e o comprometimento dos indivíduos.

\section{METODOLOGIA}

O estudo, desde o ponto de vista de seus objetivos, define-se como uma pesquisa descritiva uma vez que busca apresentar uma realidade (VERGARA, 1998) e verificar um modelo. Para tanto a população amostrada foram os funcionários de duas Instituições de Ensino Superior comunitárias do estado de Santa Catarina. O tamanho amostral foi calculado para uma significância de 5\%, chegando-se a um valor de 380 respondentes, que ocupavam diferentes cargos em diversos setores das instituições.

O instrumento de coleta de dados utilizado tinha 59 asseverações que deviam ser respondidas através de uma escala do tipo Likert, com cinco níveis de concordância, divididas em oito grandes blocos, relativos aos constructos do modelo. O questionário foi adaptado do trabalho de Moriano et. al. (2009) e foi aplicado durante o mês de Setembro de 2011 pelos autores. Ao total, obtiveram-se 382 questionários válidos.

Análise dos dados implicou no uso da Análise Fatorial Exploratória (AFE) e Confirmatória (AFC) e a Modelagem de Equações Estruturais (MEE) buscando avaliar as relações propostas entre Comportamento Intraempreendedor (CI), definido como Inovação (IN) e Assunção de Riscos (AR), Identidade Organizacional (IO) e os fatores exógenos Apoio da Direção (AD), Liberdade no Trabalho (LT), Recompensas (RC), Tempo Disponível (TD) e Incerteza no Trabalho (IT). 
Como as ideias iniciais propostas neste artigo tratam de uma verificação do modelo de Moriano et al. (2009), justifica-se então a utilização da AFC em associação com a AFE como ferramenta importante ao estudo. O agrupamento das informações correlacionadas entre si em fatores próprios, medidas por indicadores reflexivos, é um dos objetivos da análise fatorial. As variáveis juntas possuem maior significância e contribuem melhor com os modelos estatísticos (CORRAR et al., 2010). Conforme definido por Aranha e Zambaldi (2008, p.107) a AFC especificamente "procura verificar se os dados observados se comportam de acordo com uma expectativa teórica". Assim, os autores defendem que uma relação positiva reforça a teoria, mas divergências podem definir problemas com os dados, com a teoria ou com ambos. Quando o construto não era unidimensional empregou-se a AFE para selecionar as questões mais representativas do construto.

Verificada a unidimensionalidade dos diferentes construtos, usando o critério de Kaiser como delimitação do número de fatores a reter, uma variância mínima extraída de 50\% e cargas fatoriais mínimas de 0,7 (em módulo) para ter uma comunalidade mínima de 50\%, considerada satisfatória (HAIR et al., 2009; FAVERO et al., 2009), calculou-se a confiabilidade usando o alfa de Cronbach. Por fim, foi mantido um mínimo de três variáveis para cada fator, consequentemente para cada constructo.

As relações entre os constructos e as variáveis foram avaliadas pela MEE, executada de modo subsequente à AFC, utilizando o software AMOS ${ }^{\circledR}$. A MEE, conforme Codes (2005, p. 472) "caracteriza-se pela sua capacidade de especificar, estimar e testar relações hipotéticas entre um grupo de variáveis".

\section{APRESENTAÇÃO E DISCUSSÃO DOS RESULTADOS}

Conforme explicado inicialmente, neste artigo buscou-se replicar o modelo proposto por Moriano et al. (2009). Para isso, alguns passos foram dados em consonância com o trabalho anterior. Ao todo, nesta pesquisa foram avaliados oito constructos, começando pelas variáveis exógenas, a saber:

- Apoio da Direção - AD: Este era o constructo com maior número de variáveis, com dezenove questões. Descartada a unidimensionalidade com todos os indicadores, reunidos e cinco fatores adotando o critério de Kaiser, procedeu-se a selecionar as questões mais representativas. Levaram-se em conta os critérios iniciais propostos na metodologia como mínimos e, feitos os ajustes e refinamentos, escolheram-se quatro variáveis com cargas significantes $(>0,70)$, um alfa de Cronbach de 0,98 e uma variância extraída de $66 \%$. 
- Liberdade no Trabalho - LB: Inicialmente dez questões faziam parte deste constructo, mas após exclusões por falta de significância, restaram seis com cargas consideráveis e unidimensionalidade respeitada. O alfa de Cronbach somou um total de 0,90 e a variância extraída de $67 \%$.

- Recompensas - RC: Das seis questões propostas, apenas três foram empregadas na modelagem. O fator originado por estas questões possibilitou um valor de 0,86 ao alfa de Cronbach e uma variância extraída de $78 \%$.

- Tempo Disponível - TD: No questionário constavam seis variáveis a serem investigadas, das que três fizeram parte das análises posteriores. $\mathrm{O}$ alfa de Cronbach para elas atingiu 0,68 e a variância extraída apresentou $62 \%$.

- Incerteza nas Tarefas - IT: Originalmente com sete questões, a unidimensionalidade obteve-se com quatro delas. $\mathrm{O}$ alfa de Cronbach foi de 0,78 e a variância extraída totalizou $60 \%$.

- Inovação - IN: Das quatro questões, uma não apresentou os requisitos básicos e optou-se por sua eliminação. Assim o alfa de Cronbach atingiu 0,83 e variância extraída $75 \%$.

- Assumir Riscos - AR: As três questões iniciais estiveram reunidas no único fator retido segundo o critério de Kaiser, que representou uma variância extraída de 0,61 . O alfa de Cronbach foi próximo do mínimo estabelecido, com um valor de 0,68 .

Após a análise das variáveis exógenas, que se mostraram altamente significativas e com alta validade convergente (exceto TD), foi feita também a AFC da variável endógena, ora aqui posicionada como Mediadora. Para Abbad e Torres (2002, p. 21) (apud VIEIRA, 2009, p. 19) “o conceito de mediação implica suposição de relacionamento entre as variáveis envolvidas. Uma variável mediadora é aquela que, ao estar presente na equação de regressão, diminui a magnitude do relacionamento entre uma variável dependente e uma independente". Assim, considera-se que ao passarem pela mediadora, os efeitos de uma variável independente são absorvidos e retransmitidos à variável dependente. Neste artigo, a proposição inicial para avaliar é que a Identidade Organizacional é um construto mediador do Comportamento Intraempreendedor. As análises fatoriais feitas com a Identidade Organizacional deram os resultados a seguir:

- Identidade Organizacional - IO: Medida por três questões, com uma escala tipo Likert, e uma escala gráfica, teve quatro variáveis consideradas. Dela retiveram-se três, que pelo primeiro autovalor recupera uma variância de $48 \%$, próxima do mínimo estipulado. $\mathrm{O}$ alfa de Cronbach apresentou valores inferiores aos recomendados, alcançando apenas 0,43 .

Uma vez finalizadas as análises para selecionar os indicadores de cada construto, partiu-se então para a MEE, a que ficou dividida em dois momentos. No primeiro se apresenta 
o modelo sem mediação da IO para verificar as relações entre as variáveis exógenas e o Comportamento Intraempreendedor. A Figura 1 exibe o modelo sem mediação.

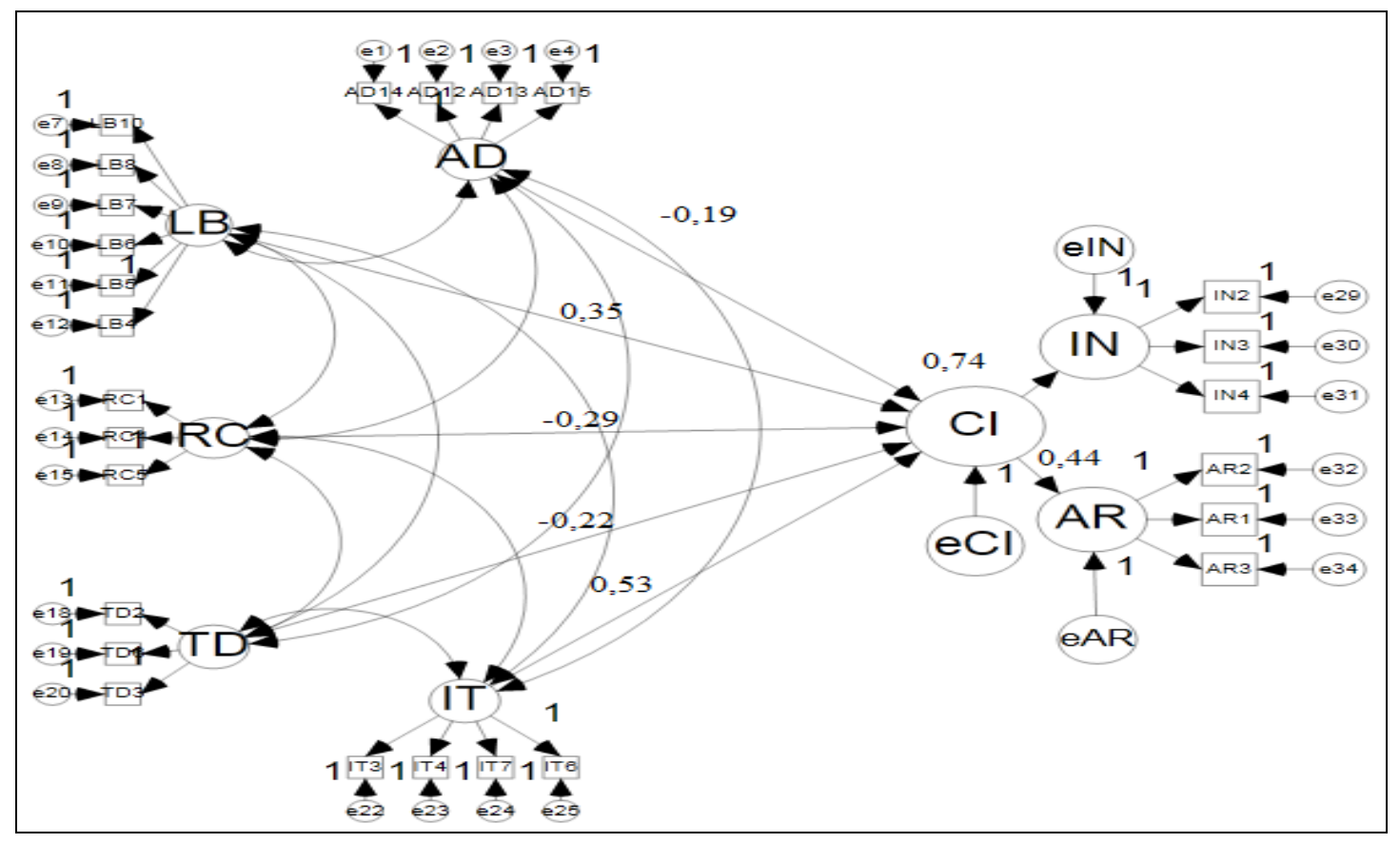

Figura 1 Modelo sem mediação da Identidade Organizacional Fonte: Elaborado pelos autores (2011)

A Figura 1 representa o diagrama de caminhos entre CI e as variáveis exógenas do modelo, elaborado com auxílio do programa $A M O S \circledR$. Nela, busca-se determinar a relação entre AD, LB, RC, TD e IT com CI, que pode ser verificado por IN e AR. Na Figura 1 não há considerações de mediações ou moderações. Inicialmente, a análise da relação entre CI e IN apresentou um coeficiente de regressão de 0,74 . Este valor representa uma forte relação entre as variáveis consideradas. Já CI e AR se mostraram menos relacionadas com um coeficiente de 0,44. Embora menor que a relação entre CI e IN, o valor encontrado também conforma uma relação significante.

Já a relação entre CI e as demais variáveis apresentou dados diversos. Diferentemente do modelo original, proposto em Moriano et al. (2009), que mostrou pouca significância entre praticamente todos os fatores organizacionais e o Comportamento Intraempreendedor, as IES estudadas apresentaram uma relação considerável entre eles. Em sequência de relevância, a IT apresentou o maior coeficiente de regressão em relação a CI, indicando que, quando bem definidas as ações, melhor será o comportamento intraempreendedor de cada indivíduo dentro das organizações. Outro fator considerável foi a Liberdade no Trabalho, com coeficiente de 0,35 que representa uma relação significativa para o modelo. Assim, ambientes com maior 
liberdade levam, nas IES pesquisadas, a um maior comportamento intraempreendedor. Por fim, tanto o TD quanto RC apresentaram coeficientes significativos, embora eles sejam negativos, de -0,22 e -0,29 respectivamente. Ao avaliar as questões aplicadas, verificou-se que as variáveis com carga fatorial acima de 0,70 em TD são aquelas que se referem à falta de tempo. Desta forma, um alto grau concordância dos entrevistados com o questionário implica em uma análise de falta de tempo disponível para as tarefas. Logo, quanto maior a utilização do tempo de trabalho, menor o tempo para buscar comportamento intraempreendedor. $\mathrm{O}$ mesmo ocorreu para recompensas onde, a concordância com as variáveis implica em falta de reconhecimento como recompensa às atividades. Logo, sempre que RC cai, significa que as atividades estão sendo reconhecidas, e isso gera recompensas. $\mathrm{O}$ apoio da direção não mostrou significância.

Para verificar a validade da mediação proposta no modelo de Moriano et al. (2009), buscou-se também aplicar a MEE entre os fatores organizacionais e a Identidade Organizacional, no intuito de determinar as relações entre ambos. A Figura 2 indica as relações propostas.

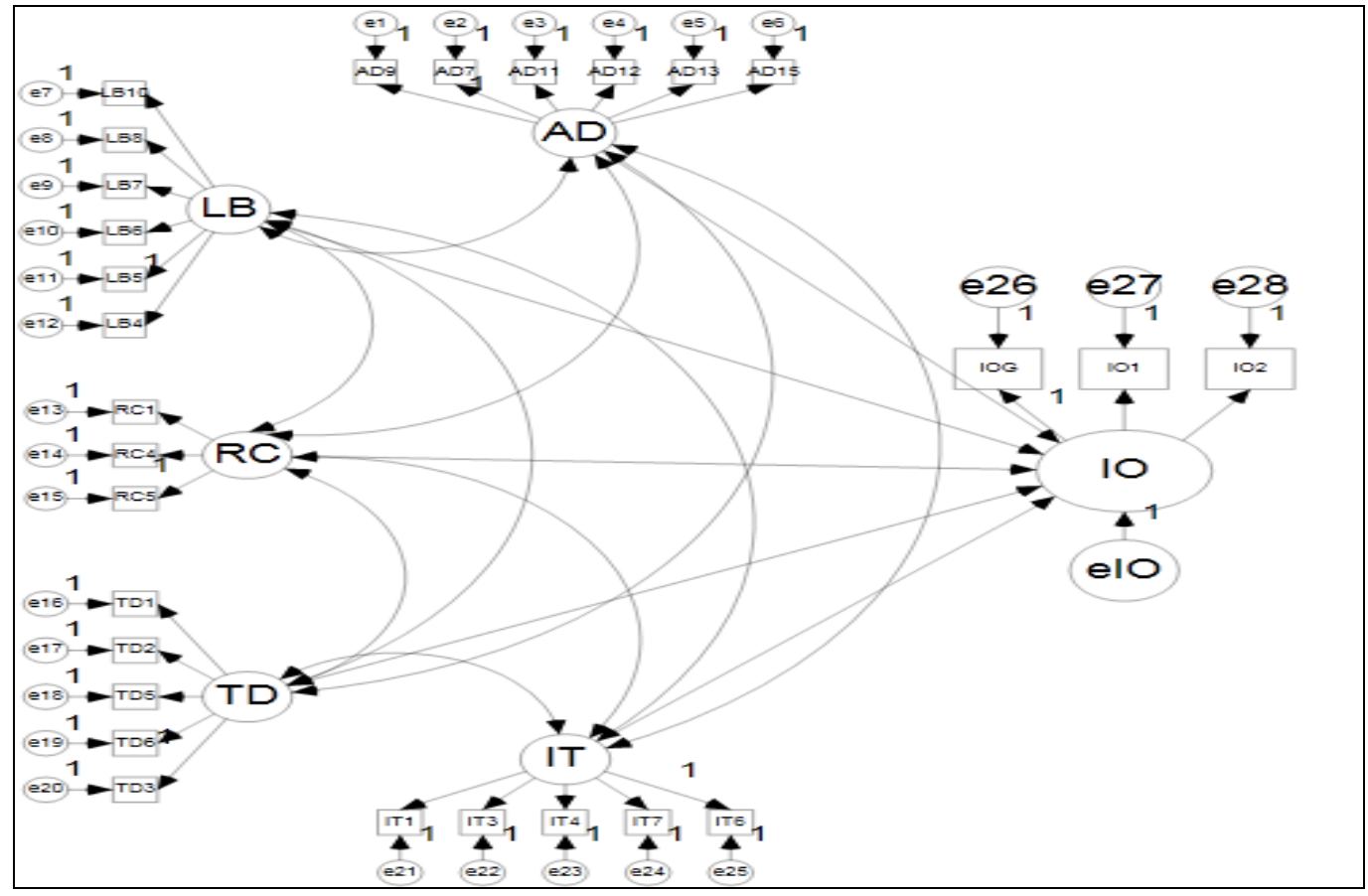

Figura 2 Modelo entre fatores organizacionais e identidade organizacional Fonte: Elaborado pelos autores (2011)

A Figura 2 apresenta valores médios de relação entre os fatores organizacionais e a Identidade Organizacional - IO. Dentre as principais relações, encontra-se o Apoio da Direção e Tempo Disponível (novamente com coeficiente negativo) com valores de 0,77 e 
0,38 respectivamente. Com uma relação considerada média, a Incerteza nas Tarefas - IT obteve um coeficiente de 0,26 . Tanto a LB quanto RC apresentaram valores não significativos (0,13 e -0,13 respectivamente). Os outputs de confiabilidade do AMOS ${ }^{\circledR}$ como GFI, CFI, RMR, RMSEA apresentaram valores inferiores aos mínimos requeridos para aceitação do modelo. Desta forma, questiona-se a validade das relações propostas pelo modelo da Figura 2.

Por fim, o último dos modelos propostos é a inserção da variável IO entre os fatores organizacionais e CI. Assim, IO poderia configurar uma relação de mediação entre os fatores e CI. Como a confiabilidade do modelo quando se relacionaram os fatores organizacionais com IO foi baixa, é possível pressupor que são grandes as chances de encontrar uma pequena confiabilidade no novo modelo.

Tal evidência pode ser verificada mediante uma série de fatores e características próprias da amostra analisada. Ao passo que o trabalho base de Moriano et al. (2009) foi feito com 120 empresas de diversos setores, o status quo de uma IES pode apresentar fatores que divergem da conclusão daqueles autores. A Figura 3 apresenta o modelo indicado com IO proposta como mediadora.

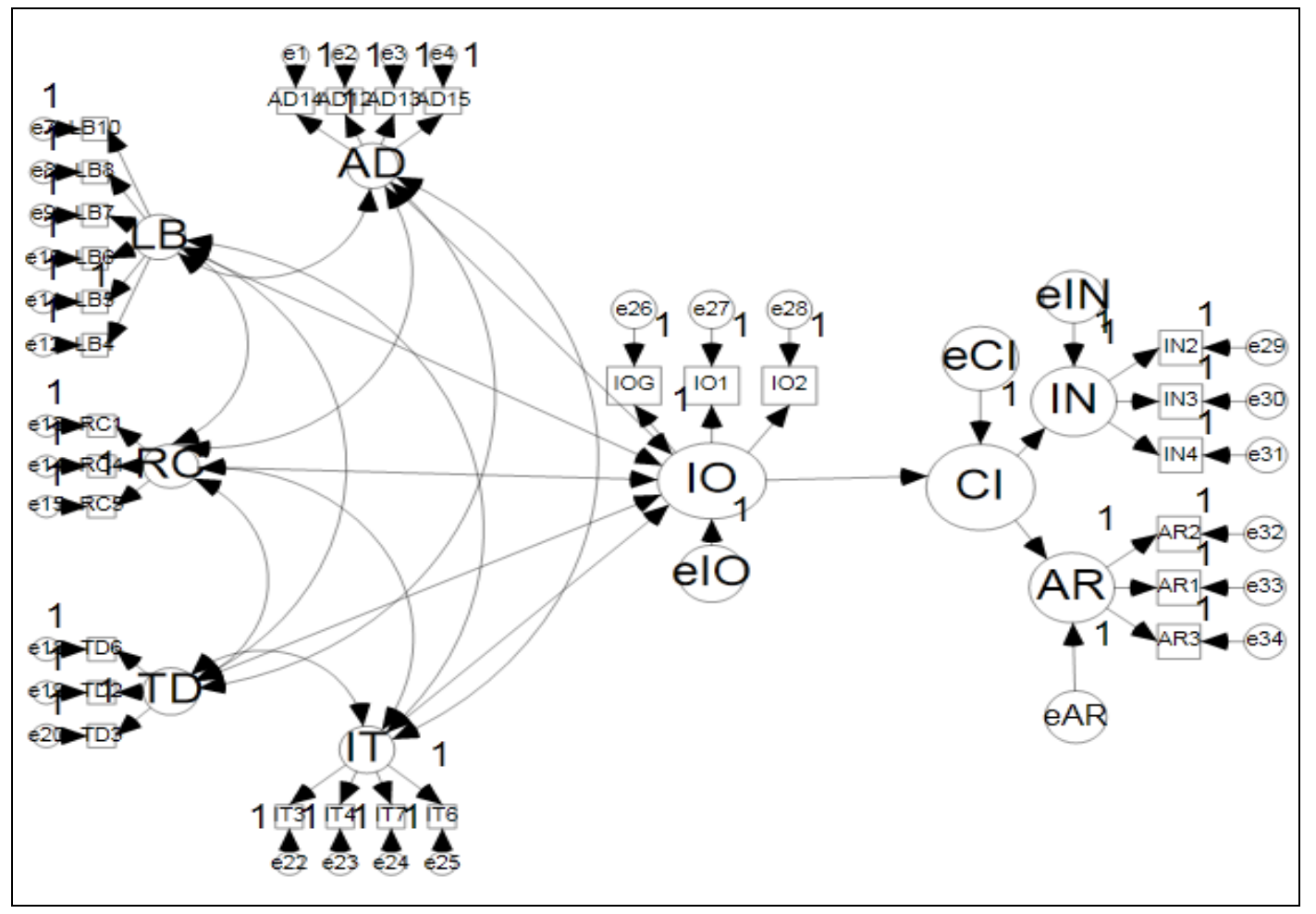

Figura 3 Modelo com Identidade Organizacional como Mediadora Fonte: Elaborado pelos autores (2011)

Conforme previsto, os valores dos outputs de confiabilidade e qualidade do ajuste do AMOS® ficaram abaixo do esperado em um modelo aceito. Tal premissa já seria suficiente 
para invalidação da IO como mediadora do Comportamento Intraempreendedor nas IES pesquisadas. Não obstante, um modelo de mediação pressupõe que as relações entre as variáveis exógenas e a variável mediadora sejam maiores que a relação entre as exógenas e a variável dependente original (HAIR et al., 2009). Não foi o que aconteceu ao processar os dados nessa configuração. Apenas em dois coeficientes dos cinco fatores organizacionais houve melhoras: $\mathrm{AD}$, que com CI possuía um coeficiente de $-0,19$ e encontrou uma boa melhora para 0,77 (conforme visto no modelo da Figura 2, AD possui boa relação com OI) e TD, de uma relação em módulo de 0,22 para 0,38. Todas as demais, LB, RC e IT, tiveram pioras em seus coeficientes. Conforme Hair et al. (2009) caso as relações entre as variáveis exógenas e a mediadora não apresentem boas relações, deve ser refutada a hipótese de mediação.

Logo, ao encontrar valores que invalidam a relação de mediação de OI para o modelo e indicadores de confiabilidade que comprometem os resultados, considera-se refutada sua mediação entre os fatores organizacionais e o comportamento intraempreendedor nas IES pesquisadas. Conforme já apontado, alguns critérios específicos da população pesquisada podem ter levado os dados a estas conclusões. Além disso, a própria forma interna de gestão das IES pode ser contrárias às ideias de Moriano et al. (2009).

\section{CONSIDERAÇÕES FINAIS}

As ações que envolvem intraempreendedorismo nas organizações são cada vez mais valorizadas e buscadas pelos gestores. Uma empresa com visão compartilhada sobre seus processos internos e interesses possui grande chance de apresentar uma conduta de gestão mais própria à competitividade global. Boas práticas e decisões empresariais podem gerar diferenciais competitivos às organizações e o intraempreendedorismo desponta como um fator de grande importância neste sentido.

Ao pesquisar nas duas IES participantes, buscou-se averiguar se nestas organizações se manifesta o intraempreendedorismo, em que se apoia, como surge e qual sua importância. Conforme abordado no início desta pesquisa, o intraempreendedorismo depende de diferentes fatores como o tamanho da organização, estrutura, uso adequado de recompensas, o apoio da administração, e a disponibilidade de recursos. Para isso, tentou-se analisar se as IES possuem ou não características próprias de gestão e, ainda, se seria possível determinar nestas organizações o intraempreendedorismo com base no modelo proposto por Moriano et al (2009), além da mediação da Identidade Organizacional. 
Para os dados analisados, foram encontrados valores significativos para determinação do Comportamento Intraempreendedor pelos fatores organizacionais propostos, a saber: Apoio da Direção, Liberdade no Trabalho, Recompensas, Tempo Disponível e Incerteza nas Tarefas. Já quando inserida a variável mediadora "Identidade Organizacional”, o modelo perde a validade. Em resumo, diferentemente do que propuseram Moriano et al. (2009), a "Identidade Organizacional" não serve como mediadora entre os fatores organizacionais e o Comportamento intraempreendedor para as IES estudadas.

\section{REFERÊNCIAS}

ABERNATHY, W. J.; CLARK, K. B. Innovation: Mapping the Winds of Creative Destruction. Research Policy, v. 14, p. 03-22, 1985.

AMABILE, T. M. Entrepreneurial Creativity. Through motivational synergy. Journal of Creativity Behavior, v.31, n.1, p. 18-25, 1997.

ANDRADE, A. R de. A gestão da universidade sob a ótica da teoria dos recursos e capacidades. In: Encontro Nacional dos Programas de Pós Graduação em Administração, 30, 2006, Salvador: Anais... Salvador. ENANPAD, 2006, CD-ROOM.

ANDRADE, A. R de. A universidade como organização complexa. Revisa de Negócios. Blumenau, v. 7, n. 3, p. 15-28, 2002.

ANTONCIC, B.; HISRICH, R. Clarifying the intrapreneurship concept. Journal of Small Business and Enterprise Development, v. 10, n. 1, p. 07-24, 2003.

ARANHA, F.; ZAMBALDI, F. Análise fatorial em administração. São Paulo: Editora Pioneira, 2008.

BERTUCCI, J. L. Percepção ambiental e estratégias gerenciais em instituições de ensino superior: uma conexão improvável. In: Encontro Nacional dos Programas de Pós Graduação em Administração, 23, 1999, Foz do Iguaçu: Anais... Foz do Iguaçu. ENANPAD, 1999, CDROOM.

CHIEH, N.; ANDREASSI, T. Intra-empreendedorismo: um estudo de caso sobre o entendimento e a aplicação dos fundamentos organizacionais associadas ao termo. In: Encontro Nacional dos Programas de Pós Graduação em Administração, set, 2007, Rio de Janeiro: Anais... Rio de Janeiro. ENANPAD, 2007, CD-ROOM.

CODES, A. L. M. Modelagem de equações estruturais: um método para análise de fenômenos complexos. Caderno CRH. Salvador, v.18, n.45, p.471-484, 2005.

CORRAR, L.J., E. PAULO \& J.M. DIAS FILHO (Coordinadores). Análise Multivariada para os Cursos de Administração, Ciencias Contábeis e Economia. 344 p., São Paulo: Atlas, 2010. 
COVIN, J. G.; SLEVIN, D. P. A conceptual model of entrepreneurship as firm behavior. Entrepreneurship Theory and Practice, v. 16, n. 1, p. 7-25, 1991.

DRUCKER, P. F. Inovação e espírito empreendedor: prática e princípios. São Paulo: ed. Pioneira, 2002.

FAVERO, L. P.; et al. Análise multivariada de dados: modelagem multivariada para tomada de decisões. Rio de Janeiro: Elselvier, 2009.

FILION, L. J. The strategy of successful entrepreneurs in small business: vision, relationships and atecipatory learning. (Thesis) - University of Lancaster, 1988.

FILION, L. J. Empreendedorismo: empreendedores e proprietários-gerentes de pequenos negócios. Revista de Administração da USP, São Paulo, v. 34, n.2, p. 5-28, abr./jun., 1999.

FILION, L. J. Entendendo os intra-empreendedores como visionistas. Revista de Negócios. v.9, n.2, p. 65-79, 2004.

GUILHON, P. de T.; ROCHA, R. A. da. Intrapreneur: multiplicador de novos negócios. Revista Alcance (Administração), Itajaí, ano VI, n. 1, p. 45-51, maio 2000.

HAIR, J. F; et al. Análise multivariada de dados. 6. ed., Porto Alegre: Bookman, 2009.

HASHIMOTO, M. Espírito empreendedor nas organizações: aumentando a competitividade através do intra-empreendedorismo. São Paulo: Saraiva, 2006.

HISRICH, R. D.; PETERS, M. P. Empreendedorismo. Porto Alegre: Bookman, 2004.

HORNSBY, J. S.; KURATKO, D. F.; ZAHRA, S. A. Middle Manager's perception of the internal environment for corporate entrepreneurship: assessing a measurement scale. Journal of Business Venturing, v. 17, p. 253-273, 2002.

IRELAND, R. D., KURATKO, D. F.; MORRIS, M. H. A health audit for corporate entrepreneurship: innovation at all levels (Part 1). Journal of Business Strategy, v.27, n.1, p.10-17, 2006.

KENNEY, M; MUJTABA, B. G. Understanding Corporate Entrepreneurship and development: A practitioner view of organizational intrapreneurship. Journal of Applied Management and Entrepreneurship, v.12, n.3, p. 73-88, Jul, 2007.

KRAUSS, S. I., FRESE, M., FRIEDRICH, C.; UNGER, J. M. Entrepreneurial orientation: A psychological model of success among southern African small business owners. European Journal of Work and Organizational Psychology, v. 14. n. 3, p. 315-344, 2005.

KURATKO, D. F.; IRELAND, R.D.; HORNSBY, J.S. Improving firm performance through entrepreneurial actions: Acordia's corporate entrepreneurship strategy. The Academy of Management Executive, v. 15, n. 4, p. 60-72, Nov. 2001. 
LUMPKIN, G. T.; DESS, G. G. Clarifying the entrepreneurial orientation construct and linking it to performance. Academy of Management Review, v.21, n.1, p. 135-172, 1996.

McCLELLAND, D. C. Entrepreneurship and achievement motivation: approaches to the science of socio-economic development. In: LEYGEL, P (org.). Paris: UNESCO, 1971.

MAZZOTTI, A. K. do A.; HOELTGEBAUM, M.; PERFEITO J. Comportamento empreendedor do gerente-proprietário de loja de materiais para construção da cidade de Medianeira - Brasil. In: SEMINÁRIO INTERNACIONAL DE LA RED MOTIVA, 7, 2006, Mar del Plata. Anais... Mar del Plata, [s. n.], 2006.

MEURER, V.; PREVIDELLI, J. de J. O empreendedorismo na área da saúde: prescrição alta ou UTI? In: ENCONTRO DA ANPAD, 2003, Anais... Rio de Janeiro, ANPAD, 2003. CDROOM.

MORIANO, J.A.; TOPA, G.;VALEOR, E.; LÉVY, J.P. Identificación organizacional y conducta "intraemprendedora". Anales de Psicología, Murcia (España), v. 25, n.2, p. 277 287, 2009.

OLIVEIRA, D. C. de; GUIMARÃES, L. de O. Perfil empreendedor e ações de apoio ao empreendedorismo: o NAE/SEBRAE em questão. In: ENCONTRO DA ANPAD, 2003, Anais... Rio de Janeiro, ANPAD, CD-ROOM, 2003.

PAIVA, F. G. de; CORDEIRO, A. T. Empreendedorismo e o espírito empreendedor: uma análise da evolução dos estudos na produção acadêmica brasileira. In: ENCONTRO DA ANPAD, 26, 2002, Salvador. Anais... Rio de Janeiro: ANPAD, CD-ROOM, 2002.

PINCHOT G., Intrapreneuring: why dont have to leave the corporation to become an entrepreneur. New York: Harper \& Row Publishers, 1985.

PINCHOT III, G.; PELLMAN, R. Intra-empreendedorismo na prática: um guia de inovação nos negócios. Rio de Janeiro: Campus, 2004.

PRYOR, A. K.; SHAYS, E. M. Growing the business with intrapreneurs. Business Quarterly, Spring, p.43-45, 1993.

SCIASCIA, S.; VITA, R. de. The development of entrepreneurship research. Milano: Liuc Papers, 2009. p. 1-19. (Serie Economia Aziendale, n. 19).

SOUZA, E. C. L. Empreendedorismo: da gêneses à contemporaneidade. 4 EGEPE - Encontro de estudos sobre empreendedorismo e gestão de pequenas empresas, 2005, Curitiba. Anais... Curitiba, 2005, p. 134-146.

SHABANA, M. A. Focusing on intrapreneurship: an employee-centered approach. Advances in Management, Kolhapur (India), v. 3, n. 12, p. 32-37, 2010.

STEVENSON, H. H; JARILLO, J. C. A paradigm of entrepreneurship: entrepreneurial management. Strategic Management Journal, v. 11, p. 17-27, 1990. 
VERGARA, S. C. Projetos e relatórios de pesquisa em administração. São Paulo: Atlas, 1998.

VIEIRA, A. V. Moderação, mediação, moderadora-mediadora e efeitos indiretos em modelagem de equações estruturais: uma aplicação no modelo de desconfimação de expectativas. Revista de Administração da USP, São Paulo, v. 44, n. 1, p. 17-33, 2009.

WEBER, M. The Theory of Social and Economic Organizations. Henderson, A. M.; Parsons, T. (trans.) New York: Oxford University Press. 1947.

ZAHRA, S.; COVIN, J. Contextual influences on the corporate entrepreneurship performance relationship: A longitudinal analysis: Journal of Business Venturing, n. 10, p.43-58, 1995.

ZILBER; S. N.; BRANCALIÃO, H. F. Da Identificação de Oportunidades à Ação Intraempreendedora: Estudo de Caso no Setor Sucroalcooleiro Brasileiro. In: XXXIII ENANPAD, 2008, Rio de Janeiro. Anais... Rio de Janeiro, ANPAD, 2008, CD-ROOM. 